\title{
A CRIAÇÃO dO CURSO dE PEDAGOGIA NO CONTEXTO DO CAPITAL MONOPOLISTA BRASILEIRO-DÉCADA 1930: UMA REFLEXÃO SOBRE A FORMAÇÃO DOCENTE
}

\author{
THE CREATION OF THE COURSE OF PEDAGOGY IN THE CONTEXT OF \\ MONOPOLISTIC BRASILEIRO-DECADE 1930: A REFLECTION ON THE TEACHER \\ TRAINING
}

José Barreto dos Santos (UEMS) ${ }^{1}$

\begin{abstract}
Resumo: O presente artigo visa analisar o processo de produção da criação do Curso de Pedagogia na década 1930, envolvendo o campo da formação profissional docente, evidenciando o método da Ciência da História para compreensão da sociedade capitalista brasileira, partindo das leis que regem suas contradições históricas no campo econômico e político. O procedimento metodológico foi trazer a compreensão histórica da condição humana com o intuito de refletir sobre a sua base material produtiva, a formação do capitalismo monopolista, que forjou as mudanças estruturais na organização do projeto nacional de educação, numa relação direta com o Projeto Nacional Desenvolvimentista. Tais reflexões tornam-se importantes para se (re) pensar o Curso de Pedagogia e a sua formação profissional docente.
\end{abstract}

Palavras-chave: Sociedade. Economia. Pedagogia. Formação Docente

Abstract: The aim of the present article is to analyze the production process for the foundation of the Pedagogy Course in the 1930's, involving the field of teacher training by bringing out the Science of History method for the understanding of the Brazilian capitalist society, based on the laws which rule historical contradictions in the economic and political fields. The methodological procedure was to bring out the historical understanding of the human condition in order to think about its productive material basis, the formation of monopolist capitalism which forged the structural changes in the organization of the national project of education, in a direct relationship with the National Developmental Project. Such reflections are important in order to (re) think the Pedagogy Course and the teacher training it offers.

Key words: Society. Political Economy. Pedagogy. Teacher Training.

\section{Introdução}

Este artigo é parte do desdobramento da minha tese de doutorado ${ }^{2}$, cujo objeto de análise incide sobre o processo de produção da criação do Curso de Pedagogia ${ }^{3}$ no Brasil na década 1930, envolvendo o campo da formação profissional docente. Processo esse, analisado a partir do desenvolvimento da base material produtiva, a formação do capitalismo monopolista brasileiro, que engendraram as mudanças estruturais de organização educacional, visando aos seguintes objetivos:

\footnotetext{
${ }^{1}$ Doutor em Educação - Professor da Universidade Estadual de Mato Grosso do Sul/UEMS.

${ }^{2}$ Concluído pela Universidade Estadual de Campinas/São Paulo.

${ }^{3}$ Criação do Curso de Pedagogia através do Decreto No. 1.190 de 04 de abril de 1939.
}

\begin{tabular}{|l|l|l|l|l|l|}
\hline Interfaces da Educ. & Paranaíba & v. 2 & n. 5 & p.58-69 & 2011 \\
\hline
\end{tabular}


evidenciar o processo econômico-social ligado à educação, abordando o desenvolvimento tardio da industrialização brasileira e a importância política da educação geral, inserindo-a no bojo da crise de 1929/30.

Nela, tornam-se compreensível o movimento de mudança das novas relações de produção monopolista, concomitantemente às contradições entre os nacionalistas e liberais em torno do projeto nacional de educação. São essas as condições materiais que vão desencadear as discussões de transição do modelo oligárquico da velha República ao modelo capitalista moderno de mercado, objetivando a sua criação, a formação profissional.

Apreender as contradições que estão patentes entre o campo material e o pensamento humano é entender o movimento histórico dos homens, como princípio educativo. Potencializar sua materialidade como momento objetivo da liberdade humana é buscar elementos fora dela, ou seja, a totalidade como categoria, no sentido de que não é ela que o cria, mas é ela quem fomenta a crítica no mundo do trabalho docente.

\section{O cenário nacional brasileiro e a conjuntura internacional}

Desde as décadas finais do século XIX, tornava-se cada vez mais evidente a preocupação com as implicações econômicas e políticas em torno da extinção do regime escravocrata e do término do regime monárquico, que são as marcas das etapas históricas, típicas do tempo que transcorre entre a colônia e o império, que se prolongou com o desenvolvimento econômico "de fora para dentro" " 4 . Tais prenúncios esbarravam na herança da cultura oligárquica, do autoritarismo, do coronelismo e do clientelismo, que facilitavam o exercício de mando patrimonial ${ }^{5}$, condicionando o processo de acumulação como padrão de dominação natural, dos que detinham o poder da terra. Ianni (1989) afirma que:

No regime oligárquico o poder é exercido sem o consentimento livremente expresso pelo povo. Isto é, o povo aquiesce, por meios não legais, tais como a tradição, a violência, a expectativa de favores ou a resignação ao status quo, encarado com estado natural. (p. 47)

É neste sentido, que o poder político da oligarquia brasileira funda-se no controle direto das elites ligadas à terra, ou seja, pela base econômica primária de subsistência e exportadora de excedentes. Que por sua vez, condicionava a existência de uma elite financeira, representada por agências ou bancos, no comércio de exportação e importação de produtos, que, também, encontravam-se inseridos no monopólio econômico de poder. Portanto, os interesses políticos fundamentais do regime, são fortemente influenciados pelos interesses dos grupos do poder, esses, funcionam como enclaves da economia de países dominantes de cunho político liberal.

[...] O produtor agrícola e o exportador, bem como o comerciante importador, prosperam dentro das coordenadas liberais, favorecidos com a troca internacional sem restrições e a mão-de-obra abundante, sustentada em mercadorias baratas. [...]. (FAORO, 1975, p. 501).

\footnotetext{
4 "de fora para dentro" - Característica da economia brasileira agro-exportadora de matéria prima e importadora de manufaturas.

${ }^{5}$ Faoro, Raymundo - Os Donos do Poder: formação do Patronato Político Brasileiro. 9. ed. São Paulo. Globo, 1991. V. 1. "O Estado torna-se uma empresa do príncipe, que intervém em tudo, empresário audacioso, exposto aos muitos riscos por amor à riqueza e a gloria: empresa de paz e empresa de guerra”. (p. 21). Característica de um Estado que não possui distinção entre os limites do público e os limites do privado.

\begin{tabular}{|l|c|c|c|c|c|}
\hline Interfaces da Educ. & Paranaíba & v. 2 & n. 5 & p.58-69 & 2011 \\
\hline
\end{tabular}
}


Assim, a vida econômica no Brasil, tange sua dependência comercial, organizada principalmente, pelas "vantagens comparativas" 6 , traçando seu movimento aos estímulos das decisões externas, viabilizada pelo livre arbítrio do mercado de consumo das manufaturas, sobretudo, com a preservação do lucro, pelas possíveis mudanças de seus padrões acumulativos.

Condições essas, que a Inglaterra aparece como destaque, pelo seu predomínio e pela defesa das teses do liberalismo econômico ${ }^{7}$. Sendo assim, a oligarquia combinava o modo operacional (modus operandi) de inspiração liberal com as práticas e os valores de tipo patrimoniais polarizados em torno dos interesses oligarcas. Conforme comenta Faoro (1975):

Liberalismo político casa-se harmonicamente com a propriedade rural, a ideologia a serviço da emancipação de uma classe da túnica centralizadora que a entorpece. [...] Esse consórcio sustenta a soberania popular - reduzindo o povo aos proprietários agrícolas capazes de falar em seu nome -, equiparada à democracia, democracia sem tutela e sem peias. A ideologia articulada aos padrões universais, irradiados da Inglaterra, França e Estados Unidos, confortando a consciência dos ocidentalizadores, modernizadores da sociedade e da política brasileira, muitas vezes enganados com a devoção sem exames de modelos. Ser culto, moderno, significa para o brasileiro do século XIX e começo do XX, estar em dia com as idéias liberais, acentuando o domínio da ordem natural, perturbada sempre que o Estado intervém na atividade particular. [...] No seio do liberalismo político vibra o liberalismo econômico, com a valorização da livre concorrência, da oferta e da procura, das trocas internacionais sem impedimentos artificiais e protecionistas. $\mathrm{O}$ produtor agrícola e o exportador, bem como o comerciante importador, prosperam dentro das coordenadas liberais, favorecidos com a troca internacional sem restrições e a mão-deobra abundante, sustentada em mercadorias baratas. (p. 501).

Neste quadro das relações econômicas e políticas, internas e externas, justapõe-se o liberalismo dos dirigentes da classe dominante com relação ao mercado. O liberalismo formal dos governantes corresponde aos compromissos inevitáveis entre as duas polarizações presentes: de um lado, a sociedade civil e a economia dependente; do outro, o que corresponde a um compromisso entre as camadas dominantes nacionais e a cultura dos países hegemônicos ${ }^{8}$.

Ao examinar as transformações ocorridas no pós Primeira Guerra Mundial, situando a organização social e econômica do período, constata-se o aprofundamento da carestia em torno das mudanças estruturais entre o Estado e a débil sociedade de classes, a frágil base material produtiva. O que, sem dúvida, não impedia a acumulação interna do capital primário, como também, fortalecia e engendrava novos valores sociais capitalistas consensuais, guiados, sobretudo, pela dinâmica da

\footnotetext{
${ }^{6}$ Ricardo, David. Princípios de economia política e tributação. Trad. Paulo Henrique Ribeiro Sandroni. São Paulo. Abril Cultural, 1982. p. 101-112. A “Lei das Vantagens Comparativas” foi enunciada por David Ricardo no início do século XIX, com finalidade de dar sustentação teórica à argumentação em favor da liberdade de comércio. Nessa época, a política comercial inglesa estava muito influenciada por diversos grupos que defendiam seus interesses particulares. Assim o protecionismo estatal, de corte mercantilista, constituía o princípio mais freqüentemente aplicado. Os defensores do livre comércio explicavam que a maior eficiência produtiva, derivada da especialização, contribuiria para a elevação do bem-estar social global, ao colocar à disposição dos consumidores maiores volumes de bens e serviços, a preços mais convenientes. Os bens seriam produzidos a um custo menor e a concorrência se encarregaria de reduzir os preços de venda via mercado.

${ }^{7}$ Tese de John Locke (1632-1704). Segundo Tratado sobre o Governo. 2. ed. São Paulo. Abril Cultural, 1978: “Embora a terra e todas as criaturas inferiores sejam comuns a todos os homens, cada homem tem uma propriedade em sua própria pessoa; a esta ninguém tem qualquer direito senão ele mesmo. $\mathrm{O}$ trabalho do seu corpo e a obra de suas mãos pode dizer-se, são propriamente dele. Seja o que for que ele retire do estado que a natureza lhe forneceu e no qual o deixou, fica-lhe misturado ao próprio trabalho, juntando-se-lhe algo que lhe pertence, e, por isso mesmo, tornando-o propriedade dele". (p. 45)

${ }^{8}$ Refiro-me, principalmente, a Inglaterra, no século XIX, e aos Estados Unidos, no século XX.
}

\begin{tabular}{|l|l|l|l|l|l|}
\hline Interfaces da Educ. & Paranaíba & v. 2 & n. 5 & p.58-69 & 2011 \\
\hline
\end{tabular}


economia sob a égide do capital pré-industrial e do Estado, criando uma esfera de novas expectativas no campo social, político e econômico.

Do ponto de vista econômico, as condições materiais associadas à diversificação da produção a livre concorrência, elevam-se, por um lado, a expansão do domínio financeiro com o "imperialismo parasitário" 9, assumido pelo capitalismo em escala mundial, por outro lado, estimulando a sociedade a novas demandas de consumo, que pouco a pouco, colocavam em xeque o arranjo da estrutura política dominante, a sua composição hegemônica neste novo ciclo a modernidade.

O final da década de 1920 e início da década de 1930 marcam o segundo ciclo desta nova fase do desenvolvimento do capitalismo, frente a crise de 1929, que passou para a história como a grande depressão mundial, que se estendeu pela década de 1930, cunhado pelos economistas de "crise de acumulação de capital". Forjava como característica o envelhecimento dos padrões de organização da produção, pela nova redefinição da divisão dos mercados consumidores, acarretando, com isso, uma nova ordenação do comércio internacional. Em outras palavras, estabelecem-se nesses anos, na primeira fase do ciclo, ou seja, a substituição da concorrência entre capital industrial e bancário, é o alinhamento desses aos novos padrões de acumulação monopolista financeiro nas bases produtivas. Assim comenta Frigotto (1995):

A crise de 1929, que é uma crise de superprodução e, portanto, uma ameaça de asfixiamento do sistema que não consegue realizar as mercadorias produzidas, determina novas estratégias para o enfrentamento da crise. Dentre estas estratégias destacam-se, no plano capitalista, o fascismo, o fordismo e o americanismo. (p.70)

Tomando em conjunto, o período de Getúlio Vargas (1930 a 1945), do Governo Provisório à ditadura do Estado Novo, o Estado brasileiro assume efetivamente o processo de produção à modernização, no controle das ações sociais e políticas, demarcando o novo estágio na acumulação do capital monopolista.

Assim, temos a ascensão do Estado Nacional varguista tendo como pano de fundo o cenário protecionista proeminente da II Guerra Mundial, dando-lhes as condições materiais necessárias aos novos arranjos na diversificação da produção agrícola e fabril. Dessa forma, o domínio do capital financeiro e industrial demarca as condições históricas do domínio imperialista na reprodução do capital ao novo ciclo assumido pelo Estado brasileiro.

Diante das condições anunciadas, o Brasil não pôde fugir à absorção do seu excedente econômico e, com isso, atrelou o seu "Projeto Nacional Desenvolvimentista" aos novos investimentos externos a sua modernização. Em entrevista à imprensa nas cidades de Petrópolis e São Lourenço, em fevereiro e abril de 1938, Vargas traçou as linhas gerais do programa econômico

\footnotetext{
${ }^{9}$ Lênin, Vladimir Ilich (1870-1924). O imperialismo: fase superior do capitalismo. Trad. Olinto Beckerman. 3. ed. São Paulo: Global, 1985. "Monopólios, oligarquias, tendências para o domínio em vez de tendências para liberdade, exploração de um número sempre crescente de nações pequenas e fracas por um punhado de nações extremamente ricas e poderosas: tudo isso originou os traços específicos do imperialismo parasitário”. (p.123)

O capital monopolista demarca os estágios do desenvolvimento do capital, que se iniciou no final do século XIX, assinalado sistematicamente por Vladimir Lênin (1985). O primeiro ciclo da fase monopólica teve seus primórdios por volta de 1870, com uma das primeiras grandes crises capitalistas, tendo gerado uma nova fase nesta sociedade, marcadas pelas seguintes características: $1^{\circ}$. Aparecimento das corporações monopólicas, a partir da centralização e concentração de capitais. $2^{\circ}$. Aumento da disputa imperialista pela repartição de áreas privilegiadas para o comércio e exportação de capitais, envolvendo tanto as empresas monopolista como as potências capitalistas. $3^{\circ}$. Fusão entre capital bancário e industrial, com o surgimento do capital financeiro. (p. 122-127).
} 
do Estado Novo, que ficaria conhecido como a "Carta de São Lourenço". Depois de enumerar alguns projetos visando desenvolver e integrar o País, afirmou:

Para esses empreendimentos é necessário mobilizarmos grandes capitais. Entretanto, não me parece que, sem maior exame, devamos continuar afirmando um exagero de expressão que resultou em lugar comum: a dependência do progresso brasileiro das inversões de capital estrangeiro e que sem ele, nada será possível fazer [...] A grande tarefa do momento, no nosso País, é a mobilização de capitais nacionais [...]. (VARGAS, 1938, p. 165-166).

Pelo exposto, o compromisso de Estado Novo foi firmado com os principais setores econômicos de infra-estrutura de base da industrialização brasileira, sob a forma de monopólio, como o elemento determinante do processo de definição de suas estratégias na realocação de recursos. Vê-se, pois, quando abortamos as estratégias do desenvolvimento nacional é que ganha sentido, os mecanismos ideológicos do capital financeiro, que cindem o movimento universal do desenvolvimento nacional, que enfatizam o consumo de bens de serviços e capital na apropriação desse excedente. Neste cenário, Singer (1968) comenta que "a primeira grande empresa, criada no País, nestes termos, foi a Companhia Siderúrgica Nacional - CSN, e se seguiram outras posteriormente, Petrobrás, Eletrobrás, Fábrica Nacional de Motores etc. (p. 224).

O itinerário nacionalista do Governo Vargas foi alicerçado no entendimento de que a emancipação econômica do Brasil, não significava confronto com o capital externo, naquele momento, muito pelo contrário, deveria ser a alavanca para elevar o Brasil ao novo patamar de desenvolvimento industrial. Reconheça-se, então, o capital parasitário teria sido o grande mentor do desenvolvimento nacional autônomo. Esse argumento ideologicamente construído a posteriore escamoteia um dado fundamental, de acordo com Nogueira (1998),

\begin{abstract}
o País, em suma, ajustava-se ao mundo e com o mundo dialogava. E o Estado precisava se converter naquele complexo de atividades teóricas e práticas com as quais a classe dirigente não só justifica e mantêm seu domínio como também consegue obter o consenso ativo dos governantes. [...] Isso quer dizer, em poucas palavras, que o Estado brasileiro, a partir de então, tornar-se-ia expressão autêntica de um projeto burguês de dominação, funcionando, na verdade, como seu executor material e espiritual. É que dada à ausência (ou rarefação) da burguesia, o Estado, atuando como seu sucedâneo, procederá como 'organismo em contínuo movimento, capaz de absorver toda a sociedade, assimilando-a ao seu nível cultural e econômico'. (p. 62-63).
\end{abstract}

A postura do Estado varguista, como imposição necessária ao enfrentamento da crise, reforçava o discurso governamental aos novos pressupostos de organização do trabalho, fundada nas teses de Frederick Taylor (1856-1915) ${ }^{10}$, Henri Fayol (1845-1925) ${ }^{11}$ e Henry Ford (1863-1947) ${ }^{12}$, que davam um novo corpo na relação capital versus trabalho assalariado. Como a forma mais elaborada da divisão do trabalho a um determinado conhecimento utilitarista e pragmático, em face do conjunto do processo de trabalho. Logo, sob o capitalismo monopolista, outras funções do

\footnotetext{
${ }^{10}$ Frederick Taylor (1856-1915) considerado o "Pai da Administração Cientificia" ao propor a utilização de métodos cientificos cartesianos na administração de empresarial. Seu foco era a eficiência e eficácia operacional na administração. (Taylorismo)

${ }^{11}$ Fundador da Teoria Clássica da Administração - Ao desenvolver estudos sobre as funções do administrador.

12 Henry Ford (1863-1947) empresário americano, fundador da Ford Motor Company foi o promotor do desenvolvimento da linha de montagem técnica e da produção em massa. (Fordismo).
}

\begin{tabular}{|l|l|l|l|l|l|}
\hline Interfaces da Educ. & Paranaíba & v. 2 & n. 5 & p.58-69 & 2011 \\
\hline
\end{tabular}


Estado estavam em curso, o de bem-estar social (Welfare State) ${ }^{13}$, no incremento das políticas públicas sociais e fiscais; como forma de controle social, na unificação das várias frações de classe dominante, ou, como forma de arrecadação de tributos e distribuição de renda.

O que reforça o compromisso do Estado na luta para obtenção de vantagens comparativas à apropriação de matérias-primas e a liberação do mercado local para os produtos manufaturados dos pólos de dominação. A segunda caracteriza-se, a cooptação do Estado pelo capital, na estrutura do sistema financeiro junto aos fatores de produção internos, na concessão de políticas de investimentos aos setores primários, na produção de excedentes, isto é, na produção de bens de serviços e capital. Caio Prado (1957) ressalta que "nestas circunstâncias a embrionária burguesia industrial da sociedade periférica fica condenada à total submissão, fazendo abortar o processo de nacionalização da economia". (p. 208).

Nesta fase, a industrialização foi o subproduto do dinamismo do capital no setor primárioexportador, dando estímulo ao desenvolvimento de forças voltadas para o atendimento do mercado interno. Na realidade afirma Singer (1998), foi o domínio do capital, que serviu como alavanca para que o modo produção monopolista dinamizasse suas "vantagens comparativas" em escala universal, com a inserção do país na era do capitalismo moderno e a sua participação no circuito mundial indicando sua dependência histórica, tanto das relações sociais, como das forças produtivas. Primeira como "consentida", posteriormente, a "tolerada", na afirmação do autor:

\begin{abstract}
Na situação de dependência consentida, a divisão de trabalho entre centro e periferia não estavam em questão. O progresso da periferia visava ao avanço de atividades agrícolas e extrativas que de modo geral não competiam com a que havia no centro. Por isso, a dependência era por suposto permanente. Na situação de dependência tolerada, o desenvolvimento almejado pela periferia destinava-se a revogar a divisão colonial de trabalho que a inferiorizava perante o centro. (p. 5).
\end{abstract}

Daí a nascente e contraditória ideologia desenvolvimentista varguista, apoiando-se na expansão do mercado interno, na relativa autonomia nos centros internos de decisão, aproveitando do isolamento da não concorrência internacional (prenúncio da II Guerra Mundial) para alavancar a formação do sistema econômico nacional, propugnando a intervenção planejadora do Estado, por meio dos investimentos vindos "de fora para dentro"; do sistema de crédito dos capitais bancários e industrial, para guiar e promover a industrialização dependente nacional e a organização do caráter parasitário assumido pelo Estado monopolista.

Portanto, captar a natureza econômica brasileira, a partir de suas origens históricas, focalizando o processo de produção na apropriação desse excedente, como também a sua utilização em torno dos interesses do capital hegemônico, tornar-se-á imprescindível para nossa apreensão, o sentido, a educação geral e a formação docente.

\title{
O Plano Nacional de Educação e a criação do curso de Pedagogia
}

Nesse contexto que o campo educacional brasileiro vem à baila das contradições econômicas, na associação do capital internacional e o Estado brasileiro, que envolvem o desenvolvimento nacional e, por outro lado, o condicionamento humano do trabalhador brasileiro frente às políticas sociais referentes às novas exigências educacionais a sua formação.

\footnotetext{
${ }^{13}$ John Maynard Keynes (1883 - 1946) defendeu uma política econômica de Estado intervencionista, através da qual os governos usariam medidas físcais e monetárias para mitigar os efeitos adversos dos ciclos econômicos - recessão, depressão e booms.
}

\begin{tabular}{|l|l|l|l|l|l|}
\hline Interfaces da Educ. & Paranaíba & v. 2 & n. 5 & p.58-69 & 2011 \\
\hline
\end{tabular}


Transportar tais pressupostos no que diz respeito ao papel da educação para a formação de professores, no processo de mudanças, onde o eixo produtivo embrionário desloca-se do campo para a cidade, da base agrícola para pequena indústria. Passa necessariamente pelo trabalhador, que deverá ter no seu currículo, exigências mínimas de uma cultura intelectual, para viabilizar o acesso a uma nova cultura, de consumo, relativas ao mercado. Isso implica destacar duas posições ideológicas da educação brasileira e a formação do professor: a visão dos liberais, representados pelos escolanovistas e, os nacionalistas representando o governo varguista.

A primeira, os escolanovistas, postulando a "defesa da escola pública", no sentido de combater a dualidade de redes por meio de uma estrutura educacional, sob a égide da escola pública. Defendia como funções básicas, o desenvolvimento da pesquisa científica empírica, com forte inspiração norte-americana, cuja finalidade é a "aspiração da sociedade ao progresso"; formar profissionais capacitados em dar respostas às mudanças no campo econômico e social.

Anísio Teixeira (1968), um dos seus mentores intelectuais, constatou que o processo de transformação em curso, dava seus sinais nos trópicos brasileiros, condicionando as modificações aos valores e as novas perspectivas de vida, escrevia o autor: "Por isso o caráter da pedagogia não é nem puramente científico e nem puramente filosófico. Ela é uma 'teoria prática"'. (p. 84).

Por outro lado, os nacionalistas consideravam ser prioridade a formação profissional, cuja finalidade é a "estabilidade política do Estado", vocacionado ao desenvolvimento econômico social da nação, com forte inspiração fascista.

\begin{abstract}
Assim é que Francisco Campos, ao propor no Decreto do Estatuto das Universidades Brasileiras a criação da Faculdade de Educação, Ciências e Letras teria que ter um caráter misto e especial, sendo provida, ao mesmo tempo, de funções culturais e de um papel eminentemente utilitário e prático. [...] O ministro conclui que a nova faculdade não seria apenas um 'órgão de alta cultura ou de ciência pura e desinteressada', mas deveria ser 'antes de tudo e eminentemente, um Instituto de Educação', cuja função precípua seria a formação dos professores, sobretudo os do ensino normal secundário. (SAVIANI, 2006, p. 36).
\end{abstract}

Nesse percurso, o Governo Provisório de Vargas, através do seu Ministro da Educação e Saúde Pública Francisco Campos ${ }^{14}$, organizou a Universidade do Distrito Federal - UDF, através do Decreto 19.852, de 04 de abril de 1931, e concomitantemente foi publicado, também, o Estatuto das Universidades Brasileiras ${ }^{15}$, que, para o ministro Campos (1940), na sua exposição de motivos do decreto, afirmava que foi como: "o mais valioso concurso do espírito revolucionário para a grande obra de reconstrução", [...] que "se processa presentemente no Brasil”. (p. 102)

Quanto à formação de professores, vale lembrar que no plano do discurso, caberia à Faculdade de Educação, Ciências e Letras, prevista no Decreto citado, a reformulação do ensino superior, que conduziria a universidade brasileira a sua finalidade "de transcender ao exclusivo propósito do ensino, envolvendo preocupações de pura ciência e de cultura desinteressada". Ditando com isso, o duplo objetivo de "equipar tecnicamente as elites profissionais do País e de proporcionar ambiente propício às vocações especulativas e desinteressadas, cujo destino, imprescindível à formação da cultura nacional” (...) ${ }^{16}$. O que para Schwartzman (1979): “A

\footnotetext{
${ }^{14}$ Ministério da Educação e Saúde Pública, criado no Brasil em 14 de novembro de 1930.

${ }^{15}$ Dispõe sobre a organização da Universidade do Rio de Janeiro. O Governo reorganizou a Universidade do Rio de Janeiro, incorporando, além dos três cursos já existentes, as faculdades de Farmácia e de Odontologia, a escola de Belas Artes, o Instituto Nacional de Música e a Faculdade de Educação, Ciências e Letras, esta última nunca implantada.

${ }^{16}$ Campos, Francisco, 1931. - Exposição de Motivos, apresentada ao Chefe do Governo Provisório, encaminhando o projeto de Reforma do Ensino Superior - In: BRASIL. Ministério da Educação e Saúde Pública. Organização Universitária Brasileira: Decretos n. 19.850, 19. 852, de 11 de abril 1931. Rio de Janeiro: Imprensa Nacional.
}

\begin{tabular}{|l|l|l|l|l|l|}
\hline Interfaces da Educ. & Paranaíba & v. 2 & n. 5 & p.58-69 & 2011 \\
\hline
\end{tabular}


simpatia que Francisco Campos manifestava pela ciência é ilusória. A pesquisa científica vinha com a arte, como ornamento indispensável, mas sem dúvida postergável”. (p. 174-175)

Contrariamente, Anísio Teixeira como Diretor de Instrução Pública do Distrito Federal, em 1931, tinha nos seus projetos universitários inúmeros apontamentos, nos quais prescrevia que, enquanto não funcionasse a Faculdade de Educação fossem ministrados cursos de férias, para aperfeiçoamento de professores em exercício no ginásio. Sobretudo, tomando as universidades como pólos autônomos de irradiação científica, literária e filosófica, na qual a pesquisa teria um valor vinculado à docência. Apesar da sua dedicação e da breve duração, a Escola de Professores foi pioneira na formação de professores primários em nível superior, de acordo com Brzezinski (1996),

a escola de Professores do Instituto de Educação da Universidade do Distrito Federal (UDF) foi criada, portanto, com objetivo de formar professores para todos os graus. Nessa mesma estrutura deveria se desenvolver a "escola" de pesquisas educacionais e de cultura superior da universidade, consolidando-se o estudo científico da educação, o que superaria o tratamento empirista até então emprestado aos problemas brasileiros. (p. 36).

No entanto, o papel do Ministro Francisco Campos no âmbito do Governo, assumia uma posição paradoxal aos princípios anunciados, contrário ao novo espírito das mudanças vindo dos liberais. Para ele, a educação não pode ser neutra e autônoma, pois ela apresenta sempre uma dimensão ética política que a condiciona. É o prenúncio legal da articulação cartorial entre o Estado e a Igreja, contrária a laicização do ensino, que já vinha sendo costurado nesses últimos anos. De acordo com Saviani (2007), a Igreja Católica primava pelos seus princípios educativos religiosos expostos na encíclica do papa Pio XI, Divini illius magistri, promulgada em 31 de dezembro de 1929.

Vê-se, que por esse motivo, o Ministro F. Campos (1931), justificativa sua posição disciplinadora da cultura do país. Sob protesto de alguns setores representativos ${ }^{17}$, a introdução do ensino religioso nas escolas por meio de argumentos de ordem religiosa no esclarecimento sobre as necessidades do país, a fim de romper com a neutralidade escolar instituída pela Constituição Brasileira de 1891, a separação do Estado com a Igreja. Segundo Campos (1931), "o fim essencial da escola é não só instruir, mas educar, não só habilitar técnicos senão também formar homens que, na vida doméstica, profissional e cívica sejam cumpridores fiéis de todos os seus deveres". (p. 312).

O compromisso político de adaptar a educação brasileira ao modelo centralizador das decisões, com forte cunho religioso, não se opõe ao caráter hegemônico do capital. O Estado Novo assume o retorno ao privilégio, ao elitismo na destinação social, no sentido de manter o caráter harmônico na defesa da política nacionalista, cujo propósito foi de criar e desenvolver uma educação adequada ao momento político e econômico que o país atravessava, ou seja, procurar dar ênfase à formação de elites e na capacitação ordeira para o trabalho do estrato mais carente da população.

Assim, o espírito revolucionário do Plano Nacional de Educação, contrariava o lançado pelo "Manifesto dos Pioneiros da Educação em 1932" "18, que se opõe política e ideologicamente, aos parâmetros ditos conservadores, em torno da educação nacional principalmente quando se pensa no projeto de universidade brasileira, na formação intelectual do educador e no campo da investigação científica.

\footnotetext{
${ }^{17}$ Comitê "pró-liberdade de consciência" em Campinas; greve dos ginasianos em São Paulo; greve de protesto dos universitários paraenses [...] e jornais: Estado de São Paulo, Estado do Rio Grande [...].

${ }^{18}$ A RECONSTRUÇÃO educacional no Brasil: ao povo e ao governo, Manifesto dos Pioneiros da Educação Nova. São Paulo. Companhia Editora Nacional, 1932.
}

\begin{tabular}{|l|l|l|l|l|l|}
\hline Interfaces da Educ. & Paranaíba & v. 2 & n. 5 & p.58-69 & 2011 \\
\hline
\end{tabular}


Dessa forma, o Estado intervencionista regulamentou e organizou a formação superior do professor brasileiro, criando oficialmente o Curso de Pedagogia, por meio do Decreto-Lei $N^{\circ}$. 1.190, de 04 de abril de 1939, organizando a Faculdade Nacional de Filosofia, a Universidade do Brasil, outorgando o chamado "Padrão Federal" às demais instituições brasileiras, incluindo, portanto, a Universidade de São Paulo/USP - Faculdade de Filosofia, Ciências e Letras, na adaptação autoritária; estruturando em "Seção", além do curso de Pedagogia no seccionado grupo dos quatro: Filosofia, Letras e Ciências; seccionando de fato os conteúdos básicos dos respectivos cursos, com a criação da Seção Especial de Didática, esquema $3+1$.

Nessa perspectiva, o projeto educativo do Estado Novo vingou em torno da "falsa crença" de formar homens "livres e conscientes", a fim de participarem de forma ativa da sociedade anunciada. Porém, para que esse processo de reprodução pudesse funcionar sem maiores traumas para o próprio modo de produção, tornou-se indispensável o controle assumido pelo Estado, que organizou o parasitismo em torno da educação geral, cooptando harmonicamente o emprego marginal e instável, de exploração capitalista, concentrando todos os seus atributos necessários da administração do Estado, para fazer, a "Escola do imperialismo", como afirma o Professor Gilberto Luiz Alves, que o "parasitismo" 19 foi a "essência do imperialismo" ${ }^{20}$, que se infiltra na base produtiva, absorvendo, assim como sanguessuga, a força do trabalho docente.

\section{Considerações finais}

Importante salientar que o Estado Novo politicamente sedimentou os ideais educacionais a modernidade a face atual, onde seus encaminhamentos foram traçados fora dos limites da economia nacional. Sobretudo, na função de plasmar uma consciência política educacional, marcada pela ausência de um entendimento humano do real modo de produção capitalista nacional e as correspondentes relações de produção.

Nesse sentido, para potencializar a força do trabalho docente às novas demandas parasitárias, no sentido de expandir os serviços mercadológicos educacionais foi necessário que o Estado assumisse a suprema direção, fixando-lhes os princípios fundamentais e controlando a execução deles, estabelecendo as "diretrizes ideológicas" com o objetivo de orientar a educação no país, bem como, "os princípios gerais de organização e funcionamento de todo o aparelho educativo do País". (Horta, 1994, p. 21)

Ao fincar suas bases nos processos técnicos e na possível profissionalização dos sujeitos que atuam nos meios de produção, nos mostram como a racionalidade funcional era levada às últimas consequências na organização do trabalho, aperfeiçoando de tal modo os objetivos monopolistas com relação ao tempo (rapidez e precisão) e a economia de recurso (eficiência e eficácia), confirmando a importância da educação profissional como princípio educativo para formação dos sujeitos, as novas formas de consolidação do trabalho. Ocultar a organização incipiente do conjunto de trabalhadores de uma possível transformação capitalista; foi a função dada à organização do trabalho docente, à proletarização do profissional da educação, acentuando a produção de excedente humano e material.

A ênfase na técnica e no profissionalismo é o reflexo da divisão do trabalho, a racionalidade da cadeia produtiva, imposta pela rubrica do Estado, veiculando o ideário das classes dominantes, no conteúdo e na forma a ser reproduzido, desestimulando, com isso, o sentido crítico humanista do educador demiurgo. Este movimento levou a uma distorção sobre sua arte e trabalho, estimulado pelo objetivo prático da técnica e do profissionalismo, aviltando o sentido necessário da educação profissional humana.

\footnotetext{
${ }^{19}$ ALVES, Gilberto Luiz. As funções da escola pública de educação geral sob o imperialismo. Revista Novos Rumos, São Paulo, Ano 5, n.16, p. 104, 1990.

${ }^{20}$ Ibid., p. 104.
} 
Além do Curso de Pedagogia, outros Cursos como Letras, Filosofia, Matemática, Física, Química, Geografia, História e Ciências Sociais, ficaram multifacetados e desconectados de seus reais pressupostos, que envolvem os conteúdos seriados pela lógica do tempo e a sua ação pedagógica, como: método, metodologia, planejamento, didática, currículo e avaliação, perdendo, assim, o sentido categórico de totalidade, na função que exerce como docente no contexto das relações sociais, solapando as contradições que as engendram, manipulando-as subalternamente, mediante objetivos e finalidades dados ao curso de Pedagogia ${ }^{21}$.

Dessa forma, dá-se início ao novo processo de acumulação e distribuição do capital financeiro, da primeira fase imperialista à fase monopolista comungando com o "Projeto Nacional Desenvolvimentista" na década 1930 e também do processo que ficou patente como legado histórico do Curso de Pedagogia, sua "falta de identidade e função"; como afirmam as pesquisadoras Carmem Silvia B. da Silva ${ }^{22}$ e Iria Brzezinski ${ }^{23}$, atribuindo aos problemas advindos da estrutura curricular do curso, no enfoque político-pedagógico que é dado ao profissionalismo, pois reflete o caráter nocivo ao subjetivismo ligado à formação educacional. Sorrateiramente, ainda representa a limitação do trabalhador da educação, sob a égide do capital, no sentido de desvalorizar o seu papel intelectual-social como professor-educador.

Isso robustece a citação de Marilena Chauí (2001), citada na introdução do seu livro: "Escritos sobre universidade" quando afirma sobre a formação pedagógica que "Cada um de nós tem tomado posição no debate, mas nem sempre pressupostos não são claros para quem nos ouve ou nos lê", eles são aparentemente fáceis, mas na realidade submetem os sujeitos ao subjetivismo danoso e pragmático, que se faz acompanhar por outras funções parasitárias, pela indústria de papel, de móveis, canetas, lápis etc., e principalmente nos dias de hoje, pela indústria editorial, na confecção dos manuais pedagógicos, como os livros específicos de didática, métodos, planejamento, metodologias, currículos, avaliação e outros ligados à formação de professores, ocultando o parasitismo imposto, na maioria das vezes, pelo próprio sujeito que erigiu sua formação pedagógica. Refiro-me a fábula chinesa citada por Gilberto Luiz Alves (1990):

\author{
Era uma vez um homem \\ que aprendeu como matar dragões. \\ e deu tudo que possuía \\ Para dominar esta arte. \\ Depois de três anos \\ ele estava totalmente preparado, mas, \\ ai dele, não teve oportunidade \\ para praticar a sua especialidade. \\ [...] como resultado, começou \\ a ensinar como matar dragões. ${ }^{24}$
}

\footnotetext{
${ }^{21}$ Refiro-me ao - Art. 01 do Decreto-Lei No. 1.190. “Objetivos: a) Preparar trabalhadores intelectuais para o exercício de altas finalidades culturais de ordem desinteressada ou técnica; b) Preparar candidatos ao magistério do ensino secundário norma ou superior e realizar pesquisas nos vários domínios da ciência, da pedagogia, da literatura e da filosofia".

${ }^{22}$ SILVA, Carmem Silvia Bissolli da. Curso de Pedagogia no Brasil: história e identidade. 2. ed. Campinas/SP. Autores Associados, 2003.

${ }^{23}$ BRZEZINSKI, Iria. Pedagogia, pedagogos e formação de professores: busca e movimento. 3. ed. Campinas, SP. Papirus, 1996.

${ }^{24}$ DSI DSCHUANG; THOM, René. As funções da escola pública de educação geral sob o imperialismo. Revista Novos Rumos, São Paulo. Ano 5, n. 16, p. 104, 1990.
}

\begin{tabular}{|l|l|l|l|l|l|}
\hline Interfaces da Educ. & Paranaíba & v. 2 & n. 5 & p.58-69 & 2011 \\
\hline
\end{tabular}


A partir dessas considerações, aplica-se o mesmo raciocínio ao que se revela inócuo, o caráter técnico e profissionalizante, dado o fato de que a qualificação profissional não é uma categoria de análise pertinente à sociedade capitalista, sem antes considerar a totalidade como categoria fundamental.

\footnotetext{
Definitivamente, no mundo contemporâneo, a especialização técnica não representa uma limitação para o trabalhador professor. A única limitação que pesa contra ele, de fato, deriva da forma pela qual a especialização profissional é explorada, sob égide do capital, no sentido de desvalorizar e embrutecer a força de trabalho. (ALVES, 1998, p. 116).
}

Entender que objetivamente o Curso de Pedagogia para formação de professores nasceu com o movimento da produção capitalista dependente, numa relação direta com o "Projeto Nacional Desenvolvimentista", na fase monopolista (década 1930), permite compreender que a crescente simplificação e objetivação do trabalho docente, a ensinar como "matar dragões", continua na esteira da barbárie humana, onde o pragmatismo parasitário adquiriu formas, ágeis e terríveis no aniquilamento dos trabalhadores da educação que ainda labutam sob o "olhar" da História, da Filosofia, das Ciências Sociais e da Letras por uma política educacional, concreta e necessária à nossa formação social, técnica e profissional. No dizer do "Velho", e tão "Novo" Marx (1974, p. 163):

\footnotetext{
Uma formação social nunca perece antes que estejam desenvolvidas todas as forças produtivas para as quais ela é suficientemente desenvolvida, e novas relações de produção mais adiantadas jamais tomarão o lugar, antes que suas condições materiais de existência tenham sido geradas no seio mesmo da velha sociedade.
}

Dessa forma, sinalizo como primordial para a atuação política dos trabalhadores da educação do nosso tempo, não é qualificação profissional anacrônica, não menos os projetos de extensão que estão em pauta hoje nas Universidades Públicas Brasileiras, que buscam a capacitação dos professores para as funções técnicas inócuas; mas, sim, o acesso ao conhecimento da real condição humana no seu sentido social histórico, do exercício coletivo, que lhes permita compreender a sociedade capitalista do nosso tempo em seu movimento histórico, econômico e político, fundamentos importantes da "Ciência da História" para as necessárias transformações da educação pública brasileira, em específico a materialidade do curso de Pedagogia e a sua formação docente.

\section{Referências}

ALVES, Gilberto Luiz. As funções da escola pública de educação geral sob o imperialismo. Revista Novos Rumos, São Paulo, Ano 5, n.16, p. 89-112, 1990.

Campinas, 1998.

A Produção da Escola Pública Contemporânea. Campinas (SP): Universidade Estadual de

BRZEINSKI, Iria. Pedagogia, pedagogos e formação de professores: busca e movimento. 3. ed. Campinas: Papirus, 1996.

CAMPOS, Francisco. Exposição de motivos do Decreto da Reforma do Ensino Superior. In: Educação e Cultura. Rio de Janeiro. Editora José Olympio. 1940.

. Exposição de motivos do decreto $\mathrm{n}^{\circ}$. 19.941, de 30 de abril de 1931. Boletim do Ministério da Educação e da Saúde Pública. nº 1 e 2, 1931, p. 312-314. 
CHAUÍ, Marilena de Souza. Escritos sobre a Universidade. São Paulo: Ed. UNESP, 2001. FAORO, Raymundo. Os donos do poder: formação do Patronato político brasileiro. 2. ed. Rev. e aumentada. Porto Alegre: Globo; São Paulo: Ed. Da Universidade de São Paulo, 1975. V.2. FRIGOTTO, Gaudêncio. Educação e a crise do capitalismo real. São Paulo: Cortez, 1995. HORTA, José Silvério Baía. O Hino, o sermão e a ordem do dia: regime autoritário e a educação no Brasil. Rio de Janeiro: Ed. UFRJ, 1994.

IANNI, Otavio. A formação do Estado Populista na América Latina. 2. ed. São Paulo: Ed. Ática, 1989.

LÊNIN, Vladimir Ilich. O imperialismo: fase superior do capitalismo. Trad. Olinto Beckerman. $3^{\text {a }}$. Ed. São Paulo. Global, 1985.

LOCKE, John. Segundo Tratado sobre o Governo. 2. ed. São Paulo. Abril Cultural, 1978.

MARX, Karl. Para a crítica da economia política. In. Marx. São Paulo: Abril cultural, , 1974. (Coleção os Pensadores)

NOGUEIRA, Marco Aurélio. As possibilidades da política: idéias para a reforma democrática do Estado. São Paulo. Ed. Paz e Terra, 1998.

PRADO JUNIOR, Caio. Esboço dos fundamentos da teoria Econômica. São Paulo. Brasiliense, 1957.

RICARDO, David. Princípios de economia política e tributação. Trad. Paulo Henrique Ribeiro Sandroni. São Paulo. Abril Cultural, 1982.

SAVIANI, Dermeval. Histórias das idéias pedagógicas no Brasil. Campinas/SP. Autores Associados, 2007. . O legado educacional do século XX no Brasil. 2. ed. Campinas/SP. Autores Associados, 2006.

SCHWARTZMAN, S. Formação da comunidade científica. São Paulo, Rio de Janeiro: FINEP, Ed. Nacional, 1979.

SINGER, Paul. De dependência em dependência: consentida, tolerada e desejada. São Paulo. Estudos Avançados. Vol. 12, número 33, maio/Agosto. 1998. . Desenvolvimento Econômico e Evolução Urbana. São Paulo. Editora Nacional, 1968.

TEIXEIRA, Anísio. Pequena introdução à filosofia da educação: escola progressiva ou a transformação da escola. São Paulo. Melhoramentos, 1968.

VARGAS, Getúlio. (1938-1945). A nova Política do Brasil. Rio de Janeiro, Editora José Olympio, 1938. 